\title{
LASER MICRO-COATING OF STAINLESS STEEL ON AN AL-SI CAST ALLOY
}

\author{
Pavel Kraus ${ }^{1}$, Iryna Hren ${ }^{1}$, Natasa Naprstkova ${ }^{1}$, Stefan Michna ${ }^{1}$, Lenka Michnova ${ }^{1}$, Aivars Aboltins ${ }^{2}$ \\ ${ }^{1}$ J. E. Purkyne University in Usti nad Labem, Czech Republic; \\ ${ }^{2}$ Latvia University of Life Sciences and Technologies, Latvia \\ pavel.kraus@ujep.cz,iryna.hren@ujep.cz,natasa.naprstkova@ujep.cz, stefan.michna@ujep.cz, \\ lenka.michnova@ujep.cz, aivars.aboltins@inbox.lv
}

\begin{abstract}
In the article investigations on opportunities to improve the properties of the surface layer obtained on Al-Si alloy by laser feeding of stainless steel 17246 into the aluminium substrate are presented. According to the reviewed literature, it can be concluded that laser surface deposition can be employed as a technique that will improve the surface properties of aluminium alloys. Aluminium alloys have wide application in the automotive, domestic and aerospace industries due to their excellent mechanical properties. One of the ways to improve corrosion and wear resistance is laser surface deposition of different alloying elements. The main aim of this study is structural changes on the layer of Al-Si cast alloy by laser austenitic stainless steel 17246 deposition. In order to remelt the Al-Si alloy surface the laser of $1.9 \mathrm{~kW}$ has been used for the facing area, and $1.6 \mathrm{~kW}$ for the edge. The linear laser scan rate of the beam was set $450 \mathrm{~mm} \cdot \mathrm{min}^{-1}$ for the facing area, and for the edge $550 \mathrm{~mm} \cdot \mathrm{min}^{-1}$. We observed that the thin surface made of austenitic stainless steel had a lot of splits. The purpose of this study is also to enhance inherent properties of surface materials to create new products or improve the existing ones. Another aim of this work was also to determine the surface properties of the Al-Si alloy after laser surface application of stainless steel 17246.
\end{abstract}

Keywords: laser deposition, austenitic stainless steel, Al-Si cast alloy, microstructure, splits.

\section{Introduction}

Laser metal deposition (LMD) is an additive manufacturing technique. This process makes use of feeding powder into the melt pool that is produced by sharply focused collimated laser beam on the substrate $[1,2]$. The existing commercial LMD system utilizes a wide range of laser technologies. The power ranges from around $1 \mathrm{~W}$ to $6 \mathrm{~kW}$, and the wave length from the ultraviolet $(354.7 \mathrm{~nm})$ to the infrared $(10.6 \mathrm{~nm})$. Requirements vary from process to process. The metallic materials, which are used for the build-up of layers, are available in fine powder. Usually powder material, which is transported to the substrate in transport gas by means of a nozzle, is used as feedstock [3; 4]. The schematic diagram of the laser metal deposition process is shown in Fig. 1.

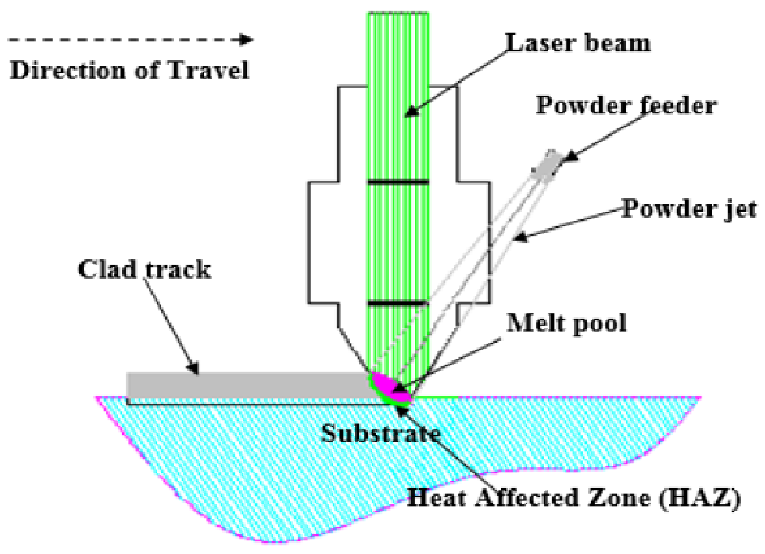

Fig. 1. Schematic of the LMD process [5]

For most engineering applications the laser, in simple terms, can be regarded as a device for producing a finely controllable energy beam, which, in contact with a material, generates considerable heat. The basic physics of laser surface treatment is simply heat generation by laser interaction with the surface of an absorbing material and subsequent cooling either by heat conduction into the interior, or by thermal radiation at high temperature from the surface of the material.

Laser surface alloying may induce extreme heating/cooling rate of $10^{4}$ to $10^{11} \mathrm{~K} \cdot \mathrm{s}^{-1}$, thermal gradient of $10^{5}$ to $10^{8} \mathrm{~K} \cdot \mathrm{m}^{-1}$ and solidification velocity as high as $30 \mathrm{~m} \cdot \mathrm{s}^{-1}$ [6]. Due to the high cooling rates, solid state diffusion can be neglected and a homogeneous and fine solidification microstructure can be achieved with a wide variety of surface compositions without the limitation of conventional 
processes, for instance, to extend solid solution and to obtain a metastable structure or even metallic glasses [7]. Various laser surface modification methods are available in Fig. 2. In laser surface alloying an additional metal is added to the melt pool to improve the surface properties. Laser transformation hardening is an autogenous technique, which involves solid-state transformation without melting of the material. The application is limited to alloys that can be treated by laser. Laser surface melting is performed by heating the alloy surface with a power high enough to create a melt pool. Laser gladding applies the same principle as laser alloying, but the difference is the depth of the substrate melted. Laser dispersion is used for forming surface composites. This technique injects a hard second phase into the melt substrate.

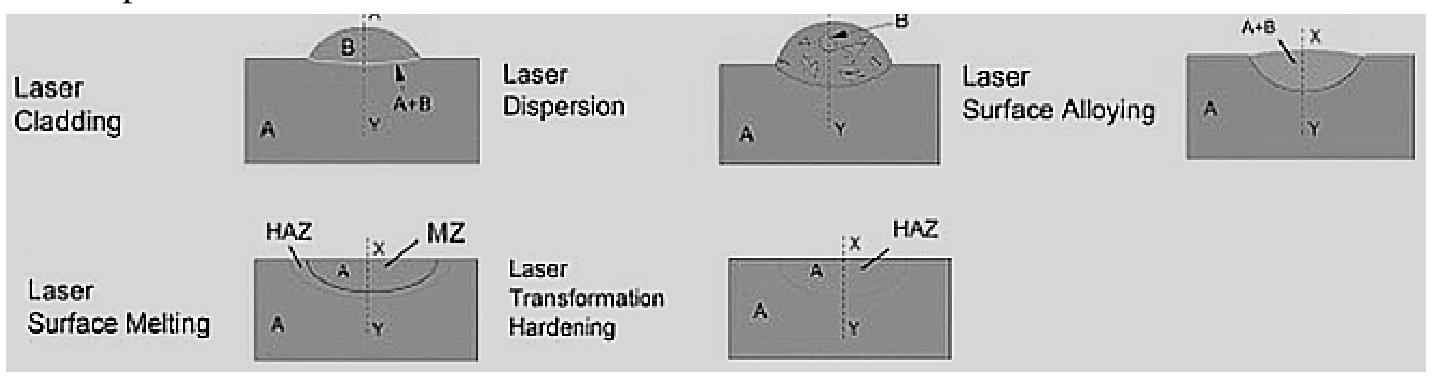

Fig. 2. Schematic of various laser surface modification methods [8]

The parameters of laser alloying are shown in Table 1.

Table 1

Parameters of laser alloying

\begin{tabular}{|c|c|c|c|}
\hline $\begin{array}{c}\text { Laser beam power, } \\
\mathbf{~ k W}\end{array}$ & $\begin{array}{c}\text { Scan speed, } \\
\mathbf{m m} \cdot \mathbf{m i n}^{-1}\end{array}$ & $\begin{array}{c}\text { Scan spacing fill } \\
\text { track, } \mathbf{~ m m}\end{array}$ & $\begin{array}{c}\text { Stainless steel } \\
\text { powder size, } \boldsymbol{\mu m}\end{array}$ \\
\hline $1.6-1.9$ & $450-550$ & 4 & $100-150$ \\
\hline
\end{tabular}

The linear laser scan speed of the beam was set $450 \mathrm{~mm} \cdot \mathrm{min}^{-1}$ for the facing area, and for the edge $550 \mathrm{~mm} \cdot \mathrm{min}^{-1}$ of the sample. The laser beam power was set $1.9 \mathrm{~kW}$ for the facing area, and $1.6 \mathrm{~kW}$ for the edge.

\section{Chemical and microscopic analysis}

Chemical analysis. The chemical composition of stainless steel powder 17246 is given in Table 2, and Al-Si alloy substrate is given in Table 3.

Table 2

Chemical composition of stainless steel powder, wt. \%

\begin{tabular}{|c|c|c|c|c|c|}
\hline $\mathbf{C}$ & $\mathbf{C r}$ & $\mathbf{N i}$ & $\mathbf{M n}$ & $\mathbf{P}$ & $\mathbf{S}$ \\
\hline 0.09 & 18.3 & 11.04 & 0.78 & 0.01 & 0.01 \\
\hline
\end{tabular}

Table 3

Chemical composition of Al-Si alloy, wt. \%

\begin{tabular}{|c|c|c|c|c|c|c|c|}
\hline $\mathbf{S i}$ & $\mathbf{F e}$ & $\mathbf{C u}$ & $\mathbf{M n}$ & $\mathbf{M g}$ & $\mathbf{C r}$ & $\mathbf{N i}$ & $\mathbf{T i}$ \\
\hline 9.1 & 0.28 & 0.023 & 0.15 & 0.39 & 0.012 & 0.0058 & 0.096 \\
\hline
\end{tabular}

Microscopic analysis. The microstructure of the deposited stainless steel powder was observed under the laser optical microscope LS3100. The microstructural evolution was investigated in order to establish the effect of surface quality of laser stainless steel deposition. Bonding and penetration of stainless steel into the Al-Si alloy (substrate) were also investigated [9; 10]. The fusion of stainless steel into Al-Si alloy was expected because of the higher density of stainless steel $\left(\approx 7.9 \mathrm{~g} \cdot \mathrm{cm}^{-3}\right)$ compared to that of Al-Si alloy $\left(\approx 2.7 \mathrm{~g} \cdot \mathrm{cm}^{-3}\right)$.

The results revealed that the stainless steel powder deposited on the Al-Si alloy was characterized with white coloration. Columnar dendritic structure was the dominant feature of the substrate. Typical microstructure of deposited stainless steel powder is shown in Fig. 3. The Figure shows the various sample regions with a lot of split on the stainless steel deposited surface. 


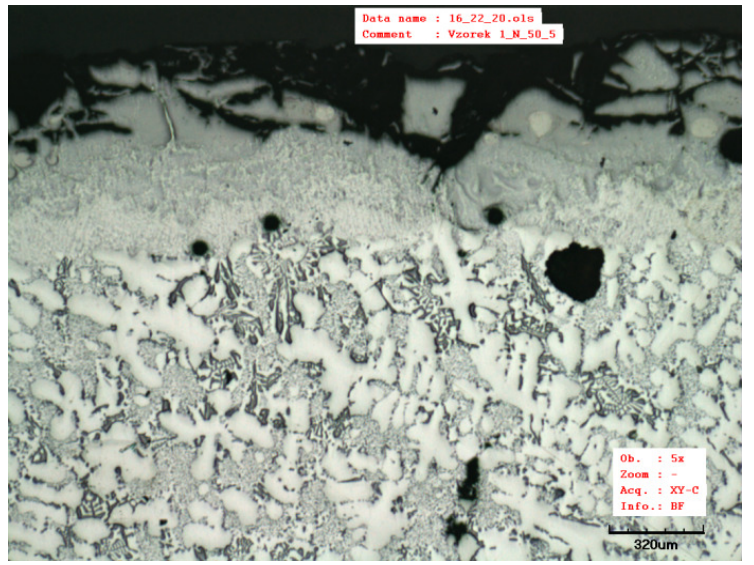

Fig. 3. Splits on the stainless steel deposited surface

Typical microstructure of the deposited stainless steel powder on Al-Si substrate with three different zones is shown in Fig. 4.

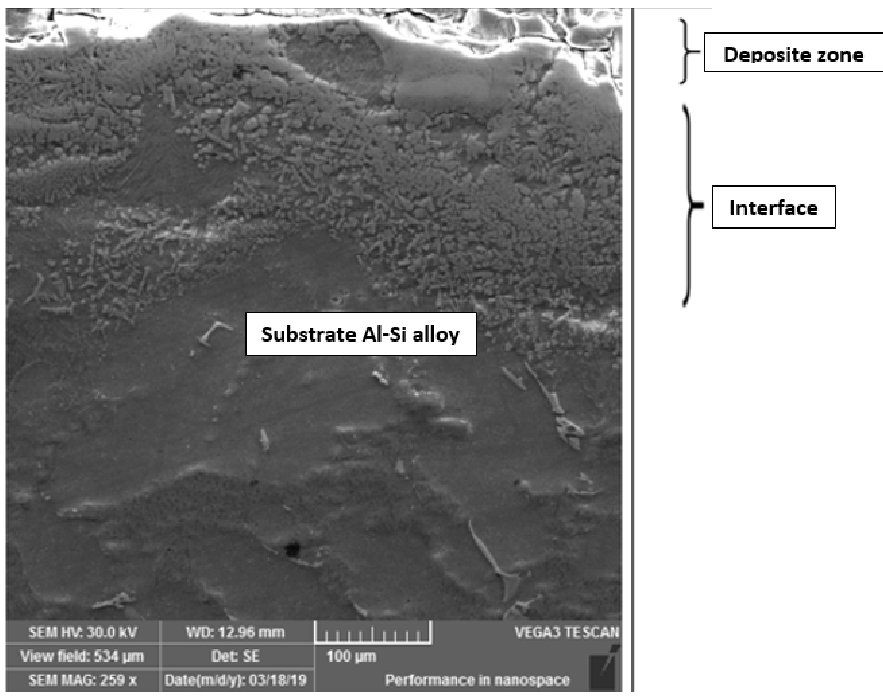

Fig. 4. Microstructure of deposited stainless steel and three zones

The Figure shows the various sample regions, such as the deposition layer with the high heat affected zone (HAZ) more than $100 \mu \mathrm{m}$. The EDS analysis proofs that in the interface layer are present such elements as Mo and Ni, Fig. 5, 6. The source of these elements is stainless steel powder.

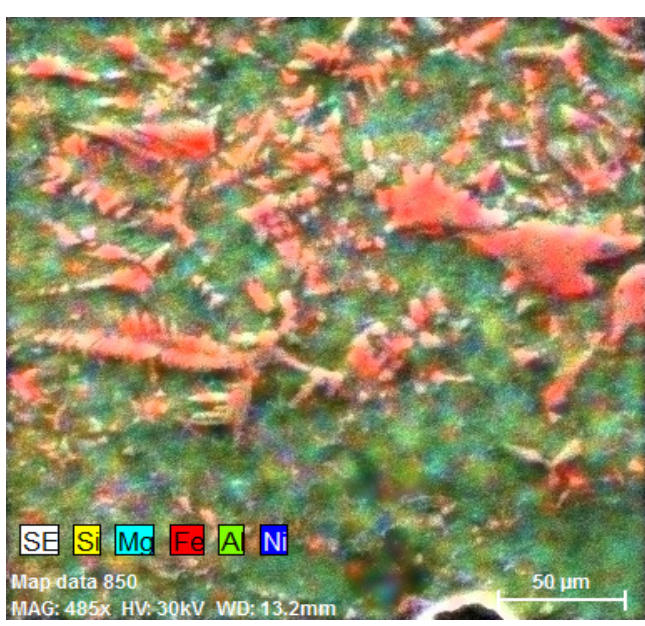

Fig. 5.Presence of Mo and Ni in the interface layer

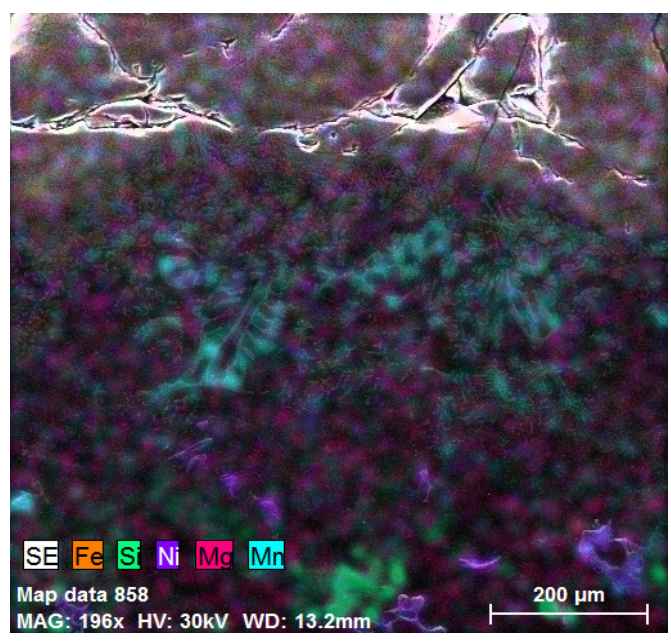

Fig. 6.Presence of Ni, Mo in the interface layer 
The measured dimensions of the deposited height (on HAZ) are presented in Table 4.

Table 4

Dimensions of deposited stainless steel track, $\mu \mathrm{m}$

\begin{tabular}{|c|c|c|}
\hline Position & Minimum & Maximum \\
\hline 1 & 650 & 746 \\
\hline 2 & 502 & 657 \\
\hline 3 & 195 & 741 \\
\hline 4 & 218 & 715 \\
\hline 5 & 206 & 666 \\
\hline 6 & 188 & 605 \\
\hline 7 & 638 & 757 \\
\hline 8 & 520 & 786 \\
\hline 9 & 522 & 836 \\
\hline 10 & 417 & 730 \\
\hline 11 & 303 & 665 \\
\hline 12 & 427 & 770 \\
\hline
\end{tabular}

\section{Surface roughness}

Surface roughness was measured according to EN ISO, DIN 4287 in longitudinal and transversal directions on the sample prepared by surface layer deposition [11].

Type of scanner TK 300, measuring path $4.80 \mathrm{~mm}$, cut off $0.80 \mathrm{~mm}$, speed $0.5 \mathrm{~mm} \cdot \mathrm{sec}^{-1}$. The results are given in Table 5 and 6 . One of the measures of the roughness profile of the laser alloyed surface with 17349 is shown in Fig. 7.

Table 5

Surface roughness in longitudinal direction, $\mu \mathrm{m}$

\begin{tabular}{|c|c|c|c|c|}
\hline $\begin{array}{c}\text { Number of } \\
\text { measurements }\end{array}$ & $\boldsymbol{R} \boldsymbol{a}$ & $\boldsymbol{R} \boldsymbol{R}$ & $\boldsymbol{R} \boldsymbol{R} \max$ \\
\hline 1 & 8.4 & 47.0 & 72.8 & 59.5 \\
\hline 2 & 9.4 & 54.1 & 70.4 & 70.4 \\
\hline 3 & 8.7 & 49.6 & 88.3 & 74.7 \\
\hline 4 & 12.9 & 59.8 & 85.1 & 85.1 \\
\hline 5 & 12.4 & 67.0 & 100.1 & 98.1 \\
\hline$\sigma$ & 1.9 & 7.2 & 10.8 & 13.1 \\
\hline$\varnothing$ & 10.4 & 55.5 & 83.3 & 77.5 \\
\hline
\end{tabular}

Surface roughness in transversal direction, $\mu \mathrm{m}$

\begin{tabular}{|c|c|c|c|c|}
\hline $\begin{array}{c}\text { Number of } \\
\text { measurements }\end{array}$ & $\boldsymbol{R} \boldsymbol{a}$ & $\boldsymbol{R} \boldsymbol{z}$ & $\boldsymbol{R} \boldsymbol{t}$ & $\boldsymbol{R} \max$ \\
\hline 1 & 8.4 & 43.6 & 65.2 & 55.23 \\
\hline 2 & 12.3 & 64.0 & 108.1 & 108.1 \\
\hline 3 & 9.9 & 44.4 & 60.9 & 60.9 \\
\hline 4 & 12.9 & 63.4 & 87.4 & 87.4 \\
\hline 5 & 14.0 & 63.3 & 99.0 & 99.0 \\
\hline$\Sigma$ & 2.05 & 9.60 & 18.47 & 20.8 \\
\hline$\varnothing$ & 11.5 & 55.74 & 84.13 & 82.13 \\
\hline
\end{tabular}

The main surface roughness parameters did not differ in both directions what also indicates the isotropy of the coating properties. 


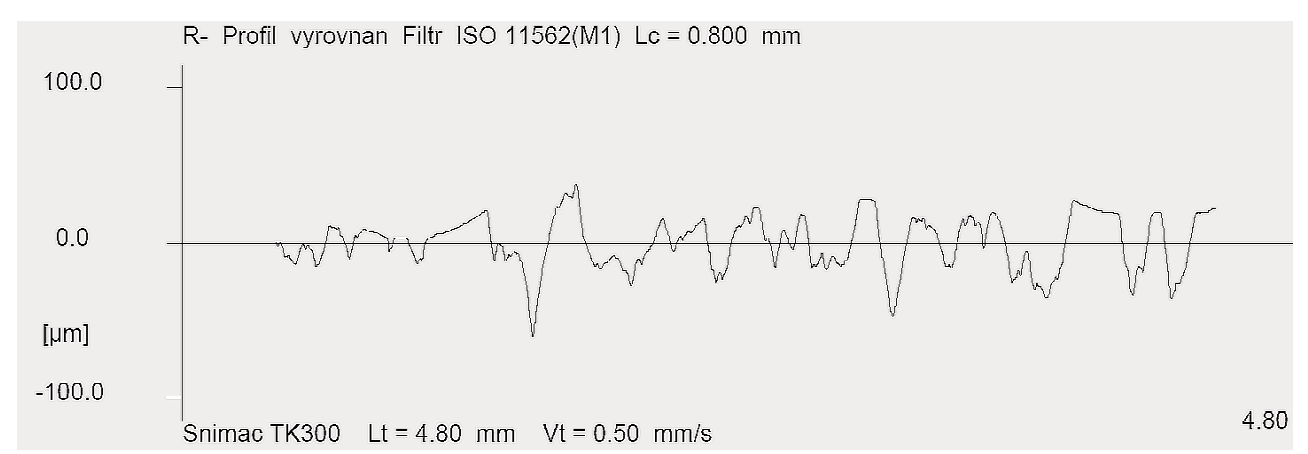

Fig. 7. Surface roughness in longitudinal direction, $R a=8.4, R z=47.0, R t=72.8$

\section{Micro-hardness}

The Vickers micro-hardness test (model FM-30) was used in the determination of the microhardness surface, Al-Si substrate, and the deposited zone through the interface zone to substrate. The micro-hardness test used a load of $300 \mathrm{~g}$, time 15 seconds. Ten indentations were taken for the measurement of the surface layer and Al-Si substrate, and the average values were taken. The results are presented in Table $7-8$. The cross-section micro-hardness is presented in Table 9.

Table 7

Micro-hardness of the surface

\begin{tabular}{|c|c|c|c|c|c|c|c|c|c|c|c|c|}
\hline Number & $\mathbf{1}$ & $\mathbf{2}$ & $\mathbf{3}$ & $\mathbf{4}$ & $\mathbf{5}$ & $\mathbf{6}$ & $\mathbf{7}$ & $\mathbf{8}$ & $\mathbf{9}$ & $\mathbf{1 0}$ & $\boldsymbol{\emptyset}$ & $\boldsymbol{\sigma}$ \\
\hline HV & 728 & 691 & 710 & 715 & 709 & 697 & 620 & 573 & 790 & 687 & 692 & 52 \\
\hline
\end{tabular}

Table 8

Micro-hardness of the Al-Si substrate

\begin{tabular}{|c|c|c|c|c|c|c|c|c|c|c|c|c|}
\hline Number & $\mathbf{1}$ & $\mathbf{2}$ & $\mathbf{3}$ & $\mathbf{4}$ & $\mathbf{5}$ & $\mathbf{6}$ & $\mathbf{7}$ & $\mathbf{8}$ & $\mathbf{9}$ & $\mathbf{1 0}$ & $\boldsymbol{\emptyset}$ & $\boldsymbol{\sigma}$ \\
\hline HV & 136 & 134 & 139 & 143 & 140 & 135 & 142 & 140 & 137 & 137 & 138 & 2.6 \\
\hline
\end{tabular}

Cross section micro-hardness

Table 9

\begin{tabular}{|c|rrr|}
\hline Depth from the edge, $\boldsymbol{\mu m}$ & \multicolumn{3}{|c|}{ Micro-hardness, HV } \\
\hline 0 & 702.7 & 795.0 & 805.0 \\
\hline 90 & 640.5 & 680.3 & 656.6 \\
\hline 180 & 327.2 & 244.9 & 221.7 \\
\hline 270 & 249.9 & 168.0 & 178.0 \\
\hline 360 & 175.7 & 140.6 & 156.9 \\
\hline 450 & 138.8 & 134.3 & 141.5 \\
\hline
\end{tabular}

The cross section micro-hardness indicates that the depth of the deposited layer is about $90 \mu \mathrm{m}$ and the interface is about $170 \mu \mathrm{m}$.

\section{Conclusions}

1. Laser deposited austenitic stainless steel powder on Al-Si alloy substrate was successfully conducted to determine the effect of the fusion of austenitic stainless steel into Al-Si alloy substrate.

2. The upper austenitic stainless steel layer shows a lot of splits.

3. The source of the presence of $\mathrm{Ni}, \mathrm{Mo}, \mathrm{Cr}$, elements in the interface layer is due to the chemical composition of the austenitic stainless steel deposition into Al-Si substrate.

4. Dimensions of the deposited austenitic stainless steel track vary from 206 to $770 \mu \mathrm{m}$.

5. The columnar dendritic structure was the dominant feature of the substrate near the interface boundary.

6. Laser surface alloying with stainless steel 17246 on Al-Si substrate could improve corrosion resistance. 


\section{Acknowledgements}

Supported by the OP VVV Project Development of new nano and micro coatings on the surface of selected metallic materials - NANOTECH ITI II., Reg. No CZ.02.1.01/0.0/0.0/18_069/0010045.

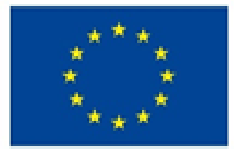

EUROPEAN UNION

European Structural and Investment Funds

Operational Programme Research,

Development and Education

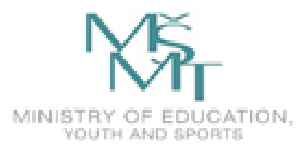

\section{References}

[1] Pakiela W. et al. The Effect of Laser Surface Treatment on Structure and Mechanical Properties Aluminium Alloy ENAC-AlMg9. Arch. Metall. Mat.,2016, Vol. 61, No. 3, pp. 1343-1350.

[2] Caiazzo F. et al. Additive Manufacturing by Means of Laser-Aided Directed Metal Deposition of 2024 Aluminium powder, Investigation and Optimization. Advanced in Mechanical Engineering, 2017, Vol. 9(8), pp. 1-12.

[3] Ma M. et al. A Comparison on Metallurgical Behaviours of 316L Stainless Steel by Selective Laser Melting and Laser Cladding Deposition. Materials Science and Engineering: A, 2017, pp. 265-273.

[4] Zhang Y., K. et al. Effect Laser Shock Processing on the Mechanical Properties and Fatigue Lives of the Turbojet Engine Blades Manufactured by LY2 Aluminium Alloy. Materials \& Design, May, 2009, pp. 1697-1703.

[5] Akinlabi E., T. et al. Advanced Coating Laser Metal Deposition of Aluminium Powder on Titanium Substrate. Proceeding of the World Congress on Engineering, June 29 - July 1, 2014, Vol. II, ISBN: 978-988-14048-0-0.

[6] Rombouts M. et al. Surface Finish after Laser Metal Deposition. Physics Procedia, 2013, Vol. 40, pp. 810-814.

[7] Yasa J., P. et al. Application of Laser Re-Melting on Selective Laser Melting Parts. Advanced in Production Engineering and Management,2011, Vol. 6(4), pp. 259-270.

[8] ASTM-International, ASM Standard F2792-12a: Standard Terminology for Additive Manufacturing Technologies, In West Conshohocken, PA: 2012.

[9] Michna Š., Hren I., Svobodová J. The Research of the Effect of High Fe Content on AlSi9NiCuMg0.5 Alloy. Manufacturing technology, 2019, Vol. 19, pp. 107-113, ISSN: 12132489.

[10] Kraus P., Náprstková N., Jirounková K., Cais J., Svobodová J. Effect of heat treatment on the microstructure of the alloy AlSi7CrMnCu2,5, Manufacturing Technology, 2019, Vol. 18, No. 4.

[11] Náprstková N., Kraus P., Novotný J. Influence of $\mathrm{Ca}, \mathrm{Sb}$ and heat treatment on AlSi9CuMnNi alloy in frame of their structure, Lecture Notes in Electrical Engineering 505,2019, pp. 581-587. 